\title{
Concordance for Type 2 (non-insulin-dependent) diabetes mellitus in male twins
}

\author{
B. Newman ${ }^{1,2}$, J.V.Selby ${ }^{1}$, M.-C. King ${ }^{2}$, C.Slemenda ${ }^{3}$, R. Fabsitz ${ }^{4}$ and G. D. Friedman ${ }^{1}$ \\ ${ }^{1}$ Division of Research, Kaiser Permanente Medical Care Program, Northern California Region, Oakland, and \\ ${ }^{2}$ School of Public Health, University of California, Berkeley, California, \\ ${ }^{3}$ Department of Medicine, Indiana University School of Medicine, Indianapolis, Indiana, and \\ ${ }^{4}$ Clinical and Genetic Epidemiology Branch, National Heart, Lung and Blood Institute, Bethesda, Maryland, USA
}

Summary. Concordance for Type 2 (non-insulin-dependent) diabetes was determined in 250 monozygotic and 264 dizygotic white male twin pairs who participated in the National Heart, Lung, and Blood Institute Twin Study. These twins were born between 1917 and 1927 and were identified from military records without regard to disease status. We examined surviving members of the cohort twice - at mean ages of 47 and 57 years - and obtained 1-h post-load glucose tests and medication histories. Diagnostic criteria for Type 2 diabetes included a glucose value $\geq 13.9 \mathrm{mmol} / 1$ or current use of antidiabetic medication; possible Type 1 (insulin-dependent) diabetic twins were excluded. A strong genetic predisposition to Type 2 diabetes was suggested by 3 lines of evidence from the second examination: (1) $58 \%$ of monozygotic co-twins of diabetic twins were themselves diabetic compared with an expected prevalence of $10 \%$; (2) only 1 of 15 originally disease-discordant, monozygotic twin pairs re- mained discordant for diabetes; and (3) $65 \%$ of non-diabetic monozygotic co-twins of diabetic twins had elevated glucose values. Because concordance for diabetes was less than 100\% for twins aged 52-65 years and because twins varied in age at onset of disease, non-genetic factors may also influence diabetes development. Among the 19 monozygotic twins pairs discordant for diabetes, diabetic twins did not differ from their non-diabetic co-twins in obesity, diet, alcohol consumption, or education. However, compared with unrelated nondiabetic twins of the same ages, non-diabetic co-twins of diabetic twins gained more weight as adults $(p<0.02)$ and had higher glucose levels $(p<0.03)$.

Key words: Diabetes mellitus, Type 2 (non-insulin-dependent), twins, genetics, medical, diseases in twins, disease susceptibility.
Twin studies have suggested the importance of genetic factors in diabetes mellitus [1-4]. A genetic influence has been inferred from the greater concordance for disease among monozygotic (identical) twin pairs than among dizygotic (fraternal) twin pairs and from the high concordance among monozygotic twins, particularly as concordance does not occur until later in life when twins no longer share the same environment. For late-onset or Type 2 (non-insulin-dependent) diabetes mellitus, concordance among monozygotic twins has ranged from $55 \%$ to $100 \%$ [5-8]. However, these studies may have overestimated disease concordance because of problems related to ascertaining diabetes in twins.

When identified from a clinical population through a diabetic proband, concordant twin pairs are twice as likely to receive medical attention as discordant pairs. In addition, concordant pairs are often of greater clinical interest and are referred more readily to investigators. Furthermore, clinic-based studies tend to include more severe cases of diabetes. Among the three clinicbased investigations of diabetes $[5,6,8]$, only Barnett et al. [5] evaluated the representativeness of their study group; they concluded that these selection biases were present.

The use of population-based twin registries provides for a wider spectrum of disease and ascertainment of twin pairs independent of disease status. However, concordance may still be overestimated if the definition of disease relies on self-reported diagnosis, because the twin of a clinical case is more likely to have been screened for - and therefore aware of asymptomatic diabetes. This overestimation can be avoided if diagnostic tests are used to evaluate all members of the registry; this was not done in the major population-based twin study on diabetes from the Danish Twin Registry [7].

To avoid ascertainment biases and overestimation of disease concordance, we investigated Type 2 diabetes mellitus in a group of twins who were recruited 
without regard to this condition. Each twin received a medical questionnaire and a $1 \mathrm{~h}$ glucose tolerance test regardless of his co-twin's status. In this paper, we report the results of analyses on disease concordance and the influence of nongenetic factors on development of Type 2 diabetes.

\section{Subjects and methods}

\section{Subjects}

The National Heart, Lung, and Blood Institute (NHLBI) Twin Study sample and its source, the National Academy of Sciences-National Research Council (NAS-NRC) Twin Panel, have been described in detail [9-11]. Briefly, the NAS-NRC Twin Panel comprises white male twin pairs born from 1917 through 1927 who served in the U.S. Armed Services sometime from World War II through the Korean War. The NHLBI Twin Study sample was drawn from NAS-NRC Twin Panel members who lived in California, New England, or within 200 miles of Indianapolis, Indiana and who agreed to participate in a study of cardiovascular disease risk factors. The 250 monozygotic and 264 dizygotic twins pairs were first examined between July 1969 and August 1973; 177 monozygotic and 186 dizygotic twin pairs were examined approximately 10 years later, between March 1981 and June 1982. Compared with the participants in the second examination, non-returnees were generally less healthy at the first examination. Of particular interest to this study, the non-returnee group had a significantly higher $(p<0.05)$ mean $1 \mathrm{~h}$ post-load glucose value but lower mean body mass index $(p<0.001)$. Participation and mortality did not differ by zygosity.

\section{Data collection}

Examination protocols were approved by the Institutional Review Boards of each participating center, and the investigations were performed in accordance with the principles of the Declaration of Helsinki. The protocols for both examinations were similar. After an overnight fast, both members of each twin pair were seen on the same day by different physicians. A $50 \mathrm{~g}$ oral glucose load was given $1 \mathrm{~h}$ before blood was drawn unless the subject was currently using insulin or oral hypoglycaemic agents or had glycosuria of $3+$ or greater. Glucose levels were measured at the examination centers us- ing an SMA 12/60 instrument (Technicon Instruments, Tarreytown, NY). Current or past use of medications, including insulin and oral hypoglycaemic agents, was ascertained. Weight and height were measured at the examinations and were obtained from military induction records and from a mailed questionnaire administered in 1967 that inquired about weight at age 25 [12].

Data on medical history, health-related behaviours, and demographic characteristics were collected at each examination. Detailed dietary information was obtained at the first examination only, from participants at all centers except San Francisco. Subjects were asked how often they ate or drank a variety of specific foods and beverages. Assuming average portion size and nutrient composition, estimates of daily intake were calculated. Alcohol consumption was measured on a 7-value scale which reflected how often the subject drank beer, wine, or other alcoholic beverages: "1" indicated seldom, and " 7 " indicated more than 4 times per day. Education was measured by the number of school years completed. When co-twins did not agree regarding the exact number of years they lived together or how often they were in contact by visits, telephone calls, or correspondence, the mean of their responses was used in the analysis.

\section{Zygosity determination}

Zygosity was assessed by serotyping 22 erythrocyte antigens $[9,10]$. Pairs were classified as dizygotic if co-twins differed for any marker. If co-twins were concordant for all markers, they were classified according to their opinion of their own zygosity. As a result, 26 twin pairs concordant for all markers were classified as dizygotic. Results of diabetes concordance analyses were essentially unchanged when these 26 pairs were reclassified as monozygotic.

\section{Diabetes diagnosis}

Criteria for a diagnosis of Type 2 diabetes included: (1) current use of insulin or oral hypoglycaemic agents and an age of at least 40 years at diabetes diagnosis, or (2) a $1 \mathrm{~h}$ post-load glucose value $\geq 13.9 \mathrm{mmol} / 1$ after a $50 \mathrm{~g}$ oral glucose load.

Because all the twins necessarily passed the military induction physical examination, men with early-onset Type 1 diabetes were excluded from the original study sample. To exclude later-onset Type 1 diabetes, 2 monozygotic twin pairs were omitted because at least 1 member of each pair was diagnosed prior to age 40 and was treated only with insulin. In addition, the sample included 4 other monozygotic and $\mathbf{4}$ dizygotic twin pairs in which at least one twin was treated with insulin for diabetes diagnosed after age 40 . Considering the

Table 1. Concordance, discordance, and prevalence of Type 2 (non-insulin-dependent) diabetes among monozygotic and dizygotic white male twins

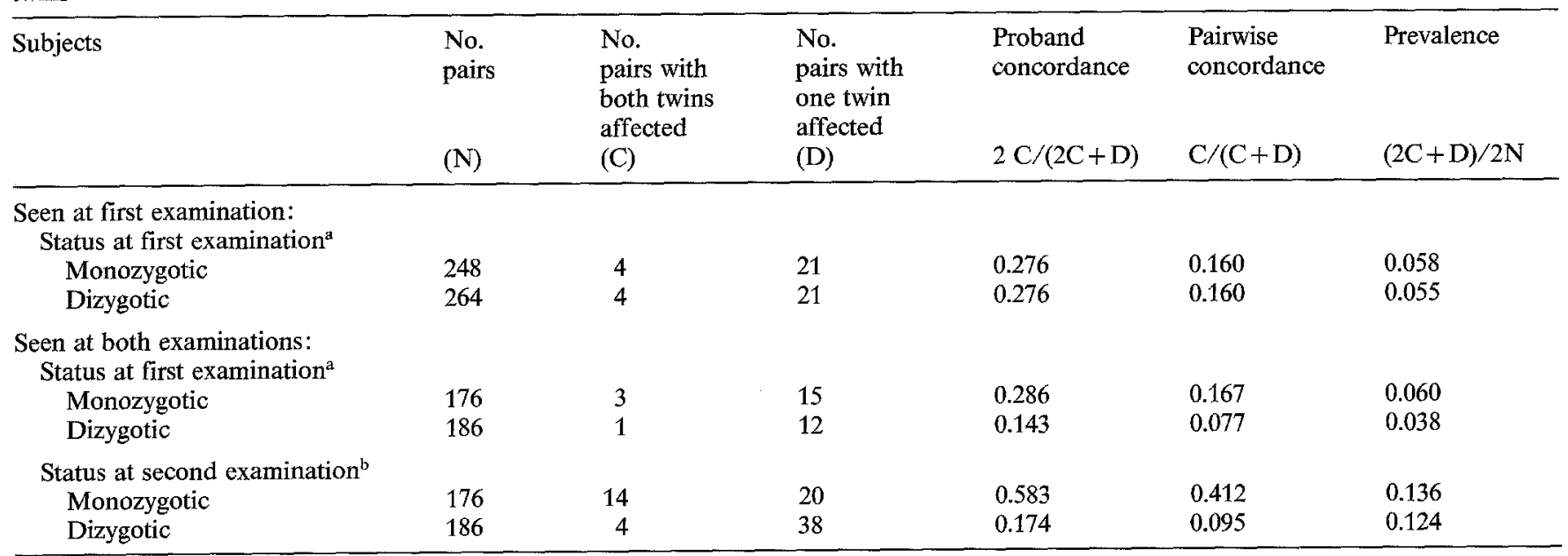

a Ages of subjects: $42-55$ years; $b$ ages of subjects: $52-65$ years 
higher incidence of Type 2 diabetes compared with Type 1 (insulindependent) diabetes in this age group and the popularity of prescribing insulin rather than oral hypoglycaemic agents during this time period, we ultimately included these twins in the reported results; exclusion of these pairs did not substantially alter the results.

\section{Statistical analysis}

Concordance was assessed using two different concordance rates, each calculated separately for monozygotic and dizygotic twin pairs $[13,14]$. The proband concordance rate is the proportion of affected individuals among twins of independently ascertained index cases (probands). This rate measures the risk of disease among co-twins of affected twins. When ascertainment is complete, as in the present study, the proband concordance rate is $2 \mathrm{C} /(2 \mathrm{C}+\mathrm{D})$, where $\mathrm{C}$ is the number of disease-concordant pairs and $\mathrm{D}$ is the number of diseasediscordant pairs. For comparison with other studies for which the proband concordance rate was not available, we have also presented the pairwise concordance rate, simply the proportion of all affected twin pairs in which both members are affected, i.e. $C /(C+D)$.

To investigate the association between environmental or behavioural factors and the development of Type 2 diabetes while controlling for a genetic predisposition to the disease, matched-pair analyses were conducted using those discordant monozygotic pairs in which both twins were nondiabetic at the first examination. Twins in whom diabetes subsequently developed were compared with their unaffected co-twins by matched-pair Student's t-tests for measures of glucose, obesity, education, and diet obtained prior to diabetes diagnosis. To assess the similarity between the unaffected co-twins from the diabetes-discordant pairs and other subjects without diabetes, the nondiabetic co-twins were compared with a sample comprising 1 monozygotic twin from each pair with no evidence of diabetes in either twin. Standard Student's t-tests were used to evaluate the differences between these 2 groups in glucose, obesity, diet, and education measured at or before the first examination.

\section{Results}

Prevalence and concordance for Type 2 diabetes are presented in Table 1. Values from the first examination also are presented for twin pairs who returned for the second examination. No difference in concordance between monozygotic and dizygotic twins was seen at the first examination when mean age of the group was 47 years and prevalence of the disease was $5.7 \%$. Ten years later, prevalence was approximately $13 \%$ and the proband concordance rate reached $58.3 \%$ for the monozygotic twins. Among disease-discordant pairs of monozygotic twins at the second examination, $65 \%$ (13 of 20) of non-diabetic twins had $1 \mathrm{~h}$ post-load glucose values between 11.1 and $13.8 \mathrm{mmol} / \mathrm{l}$.

Monozygotic twins who returned for the second examination were representative of all monozygotic twins at the first examination in regard to prevalence and concordance of Type 2 diabetes. However, dizygotic twin pairs who remained in the study had a lower prevalence and proband concordance for Type 2 diabetes than those who did not. Thus, the decrease in diabetes concordance observed among dizygotic twins between the first and second examinations is at least partly an artifact of the subset of dizygotic twins who returned. For this reason, we did not compare monozy-
Table 2. Prevalence and proband concordance for Type 2 diabetes at the second examination among 176 pairs of monozygotic white male twins by various diagnostic criteria ${ }^{a}$

\begin{tabular}{lllll}
\hline $\begin{array}{l}\text { Diagnostic } \\
\text { cutpoint } \\
\text { for glucose } \\
\text { tolerance test }\end{array}$ & $\begin{array}{l}\text { No. pairs } \\
\text { with both } \\
\text { twins } \\
\text { affected }\end{array}$ & $\begin{array}{l}\text { No. pairs } \\
\text { with one } \\
\text { twin } \\
\text { affected }\end{array}$ & Prevalence & $\begin{array}{l}\text { Proband } \\
\text { concor- } \\
\text { dance }\end{array}$ \\
\hline$\geq 13.9 \mathrm{mmol} / 1$ & 14 & 20 & 0.14 & 0.58 \\
$\geq 12.5 \mathrm{mmol} / 1$ & 20 & 31 & 0.20 & 0.56 \\
$\geq 11.1 \mathrm{mmol} / 1$ & 35 & 38 & 0.31 & 0.65 \\
\hline
\end{tabular}

a A diagnosis of Type 2 diabetes is made on the basis of current use of medication or a $1 \mathrm{~h}$, post-50 g-load glucose tolerance test result equal to or greater than 1 of the 3 cutpoint values indicated

Table 3. Contact (as measured at first examination) among monozygotic white male twin pairs concordant for Type 2 diabetes, discordant for diabetes, or concordant for no evidence of diabetes at the second examination

\begin{tabular}{lrll}
\hline & $\begin{array}{l}\text { No. } \\
\text { pairs }\end{array}$ & $\begin{array}{l}\text { No. years } \\
\text { lived together } \\
\text { (mean } \pm \text { SD) }\end{array}$ & $\begin{array}{l}\text { No. }(\%) \text { pairs } \\
\text { with at least } \\
\text { weekly contact }\end{array}$ \\
\hline $\begin{array}{lrll}\text { Both twins affected } \\
\text { One twin affected }\end{array}$ & 14 & $21.4 \pm 2.9$ & $11(79)$ \\
Neither twin affected & 142 & $22.7 \pm 6.9$ & $6(30)$ \\
\hline
\end{tabular}

a Contact refers to how often twins see, call, or write to each other

gotic and dizygotic concordance estimates at the second examination, and the remainder of the analyses focused primarily on the more reliable monozygotic twin sample.

As shown in Table 2, different diagnostic glucose tolerance criteria influenced prevalence figures greatly but had little effect on concordance estimates. Whereas prevalence steadily increased with a decrease in the glucose tolerance test level used for diagnosis of Type 2 diabetes, concordance estimates were independent of the threshold value. To maximize diagnostic specificity and predictive value, we used a $1 \mathrm{~h}$ postload glucose level of $\geq 13.9 \mathrm{mmol} / 1$ as part of the diagnostic criteria in all subsequent analyses.

Among the 21 twin pairs discordant for diabetes at the first examination, monozygotic twins were more likely to have become concordant when seen at the second examination (7 pairs) than to stay discordant (1 pair). In 7 other pairs, neither twin met our criteria for Type 2 diabetes at the second examination. Because 6 of the 21 discordant monozygotic twin pairs did not return for the second examination, these rates of change are minimum estimates. (In contrast, only 1 pair among the 21 disease-discordant dizygotic twin pairs became concordant for Type 2 diabetes; 3 pairs became concordant for no disease, 8 remained discordant, and 9 did not return for the second examination.) Of the twins who were apparently diabetic at the first but not at the second examination, 5 (3 monozygotic and 2 dizygotic) had either lost at least $5 \%$ of their first-examination weights or had glucose levels that 
Table 4. Environmental and behavioural factors measured prior to onset of Type 2 diabetes for monozygotic white male twins: comparison of diabetic twins, their non-diabetic co-twins, and other non-diabetic twins

\begin{tabular}{|c|c|c|c|c|c|c|c|c|}
\hline \multirow[b]{3}{*}{ Glucose (mmol/1) } & \multicolumn{5}{|c|}{ Disease-discordant pairs ${ }^{\mathbf{a}}$} & \multicolumn{3}{|c|}{ Other non-diabetic twins ${ }^{b}$} \\
\hline & $\begin{array}{l}\text { Sample } \\
\text { size }\end{array}$ & \multicolumn{2}{|c|}{$\begin{array}{l}\text { Diabetic } \\
\text { twin } \\
\text { Mean } \pm \text { SD }\end{array}$} & \multicolumn{2}{|c|}{$\begin{array}{l}\text { Non-diabetic } \\
\text { co-twin } \\
\text { Mean } \pm \text { SD }\end{array}$} & $\begin{array}{l}\text { Sample } \\
\text { size }\end{array}$ & \multicolumn{2}{|c|}{ Mean $\pm S D$} \\
\hline & 18 & $10.7=$ & $1.5^{\mathrm{c}}$ & $9.6 \pm$ & 1.7 & 151 & $8.3 \pm$ & $2.3^{\mathrm{d}}$ \\
\hline \multicolumn{9}{|l|}{ Body-mass index $\left(\mathrm{kg} / \mathrm{m}^{2}\right)$} \\
\hline at induction & 19 & $21.9=$ & 2.8 & $21.9 \pm$ & 2.6 & 155 & $21.8 \pm$ & 2.1 \\
\hline \multicolumn{9}{|l|}{ Daily dietary intake } \\
\hline total calories & 17 & $2,047=$ & & $2,095 \pm 5$ & & 145 & $1,985 \pm$ & 602 \\
\hline protein $(\mathrm{g})$ & 17 & $77=$ & 22 & $84 \pm$ & & 145 & $73 \pm$ & 22 \\
\hline fat $(\mathrm{g})$ & 17 & $94=$ & 42 & $94 \pm$ & 35 & 145 & $89 \pm$ & 33 \\
\hline carbohydrates (g) & 17 & $225 \pm$ & 65 & $227 \pm$ & & 145 & $223 \pm$ & 74 \\
\hline simple carbohydrate (g) & 17 & $120 \pm$ & & $140 \pm$ & & 145 & $131 \pm$ & 44 \\
\hline
\end{tabular}

${ }^{a}$ Includes 19 monozygotic twin pairs in which neither twin had diabetes at the first examination by study criteria and in which 1 twin remained non-diabetic while his co-twin subsequently became diabetic before the second examination; $b$ Includes all monozygotic twins who came from pairs with no evidence of diabetes and who had $1 \mathrm{~h}$, post-load glucose levels less than $11.1 \mathrm{mmol} / 1$ at the second examination; ${ }^{\mathrm{c}} p<0.05$ when compared to the group of non-diabetic co-twins using matched-pair Student's t-test; $d p<0.05$ when compared to the group of non-diabetic co-twins using standard Student's t-test

were still elevated $(\geq 11.1 \mathrm{mmol} / \mathrm{l})$ at the second examination; the other 5 previously hyperglycaemic twins no longer had elevated glucose levels despite no evidence of weight change, of diabetic diet, or of medication use.

To assess whether environmental or behavioural similarity within monozygotic twin pairs could account for the observed concordance for Type 2 diabetes, we compared degree of contact between co-twins in disease-concordant and disease-discordant monozygotic twin pairs (Table 3 ). No appreciable differences by concordance status were seen for the number of years twins lived together. However, disease-concordant twins were more likely to be in current weekly contact with each other than were other twin pairs.

In 19 of the 20 monozygotic twin pairs discordant at the second examination, the diabetic twin was diagnosed with Type 2 diabetes after the first examination. Diabetes risk factors collected at the first examination or earlier (i.e. before diabetes was diagnosed) were compared for diabetic twins, their non-diabetic cotwins, and other nondiabetic monozygotic twins (Table 4). When evaluated by matched-pair Student's t-tests, the diabetic twins and their unaffected twin brothers did not differ significantly for any of the measures of obesity, alcohol consumption, diet, or education, but $1 \mathrm{~h}$ post-load glucose values were significantly higher among the diabetic twins $(p<0.02)$. When the nondiabetic twin brothers of diabetic twins were compared with other non-diabetic monozygotic twins using standard Student's t-tests, the twin brothers of diabetic twins had significantly higher $1 \mathrm{~h}$ post-load glucose values $(p<0.03)$ and were more obese later in life ( $p<0.02$ at the first examination).

\section{Discussion}

The results of this study strongly suggest the importance of genetic factors in the development of Type 2 diabetes. Type 2 diabetes developed in $58 \%$ of co-twins of diabetic monozygotic twins by 52-65 years of age. In contrast, the national prevalence of Type 2 diabetes among white men in the same age range is $10 \%$ (including previously diagnosed and undiagnosed Type 2 diabetes) [15]. Thus, the risk of Type 2 diabetes developing in monozygotic twin brothers of diabetic twins is nearly six-fold higher than in their peers. Furthermore, only 1 of 15 originally disease-discordant monozygotic twin pairs who returned for the second examination remained discordant for diabetes, and $65 \%$ of the nondiabetic monozygotic twin brothers of diabetic twins had elevated glucose tolerance levels at the second examination.

The similar concordance for monozygotic and dizygotic twins at the first examination emphasises the influence of age on concordance of Type 2 diabetes in twins. Among monozygotic twins, 11 pairs became concordant for diabetes between the first and second examinations. At least 19 pairs became newly discordant, and among these pairs, a large proportion of the nondiabetic twins had elevated post-load glucose levels at the second examination. Because these twins are still at high risk for Type 2 diabetes [16], concordance is likely to increase with continuing follow-up. Barnett et al. $[5,17]$ observed a similar tendency in their longitudinal study. Thus, our results are not inconsistent with the other twin and family studies [1-8].

The degree of bias in our findings due to selective exclusion of twins with Type 2 diabetes is likely to be 
quite small. At the military induction examination, potential recruits were not regularly excluded from the Armed Services for obesity or glycosuria unless clinically diagnosed diabetes was found [18]. Because of their young ages, most of these diabetic men probably had Type 1 diabetes. Underenrollment of affected twins in this study [19] also is not suggested by comparison with national statistics: the prevalence of Type 2 diabetes among white men aged $45-54$ years is $6.7 \%$ [15] compared with $5.7 \%$ among our slightly younger twins at the first examination. Finally, possible selective loss of twins with Type 2 diabetes due to death during the interval between the first and second examinations was investigated by a review of death certificates. Among the 21 deceased monozygotic twins, 14 death certificates suggested cardiovascular disease as an underlying or associated cause of death, but none specifically mentioned diabetes. Mean values of glucose tolerance and body mass index from the first examination for these 14 twins did not differ significantly from twins who survived.

Disease concordance within twin pairs may be due to both genetic and environmental similarity. Twin pairs concordant for Type 2 diabetes were more likely to be in current, frequent contact than were discordant twin pairs, suggesting that environmental or behavioural factors which occur later in life may influence the development of diabetes. Additional evidence for environmental influences was suggested by less than $100 \%$ concordance and by variation in age at diabetes onset between monozygotic twins.

Comparison of monozygotic co-twins discordant for diabetes provides an appealing approach for identifying nongenetic risk factors because it controls for genetic predisposition to disease. However, among the 19 discordant monozygotic twin pairs, body mass at various ages, education, diet, and alcohol consumption measured prior to diabetes diagnosis were virtually identical for diabetic twins and their unaffected twin brothers. The elevated glucose tolerance levels at the second examination for many of these unaffected twin brothers of diabetic twins may indicate impending onset of diabetes; similarity in risk factor levels between diabetic twins and their apparently unaffected co-twins may therefore not be surprising.

Confirming the importance of adult weight gain in the development of Type 2 diabetes, the diabetic twins and their nondiabetic twin brothers gained substantially more weight than did the other nondiabetic twins during the adult years prior to development of diabetes despite virtually identical mean body mass indices in early adulthood. Whether this weight change occurred for environmental or genetic reasons cannot be determined. Perhaps the gene or genes responsible for susceptibility to Type 2 diabetes also contribute to obesity. On the other hand, a role for adult weight gain as a nongenetic risk factor is suggested by the 1 monozygotic twin pair that remained discordant for diabetes more than 10 years: although both twins gained weight, the diabetic twin weighed more than his nondiabetic brother at induction ( $83 \mathrm{~kg}$ versus $78 \mathrm{~kg}$ ) and gained more by the first examination ( $33 \mathrm{~kg}$ versus $23 \mathrm{~kg}$ ). The nondiabetic twin did not gain additional weight between the first and second examinations.

Our diagnoses of Type 2 diabetes were based on criteria that differ from the recommendations of the National Diabetes Data Group (NDDG) [20] and World Health Organization [21]. At the first examination, which occurred prior to the development of these guidelines, glucose tolerance was measured at $1 \mathrm{~h}$ as was commonly done in epidemiologic studies of that time. For the sake of comparability, the same test was repeated at the second examination rather than changing to a fasting or $2 \mathrm{~h}$ value.

Haffner et al. [22] found that the 1-h glucose value of $11.1 \mathrm{mmol} / 1$ following a $75-\mathrm{g}$ glucose load had a sensitivity of $93.6 \%$ and a specificity of $90.4 \%$ in Anglo-Americans when compared with the NDDG criteria. Raising the diagnostic criteria to $13.9 \mathrm{mmol} / 1$ increases specificity to $98.8 \%$ whereas sensitivity declines to $56.3 \%$ (S.M.Haffner, personal communication). As we primarily wished to exclude false-positive diagnoses, we chose the higher threshold. Although the sensitivity of our criteria is theoretically quite low, the $12-13 \%$ prevalence observed among our twins at the second examination resembles the $10.4 \%$ prevalence shown in data from the National Center for Health Statistics [15]. Our specificity may be better than expected because the glucose load was $50 \mathrm{~g}$ instead of $75 \mathrm{~g}$. However, even with this high degree of specificity, there probably were false-positive test results: 10 twins (including 1 who was taking medication) were categorised by our criteria as diabetic at the first examination but not at the second examination. Only 5 of these had lost weight or still had elevated glucose levels that were below our diagnostic threshold. This probably reflects the lack of reliability of glucose tolerance tests in general and particularly the $1 \mathrm{~h}$ value [23].

Thus, more complete and unbiased ascertainment of late-onset diabetes among monozygotic twins supports a strong genetic predisposition, at least among white men. The susceptibility of other racial or ethnic groups who have very different rates of Type 2 diabetes and glucose tolerance distributions may result from different underlying genetic or environmental mechanisms [24]. Unfortunately, significant estimates of monozygotic twin concordance do not distinguish among a variety of genetic modes of inheritance, from single genes with incomplete penetrance to multifactorial inheritance $[14,25]$. Consequently, elucidating a specific genetic basis and the role of environmental or behavioural factors in the phenotypic expression of the diabetes genotype requires further investigation of twins and families as well as longitudinal population-based research. Our results suggest that genetic marker studies of disease-discordant dizygotic twins may be 
particularly informative for identifying the gene or genes responsible for susceptibility to Type 2 diabetes, especially if the co-twins are similar with respect to obesity. Further attention to disease-discordant monozygotic twin pairs in which the non-diabetic co-twin does not exhibit metabolic abnormalities will also help our understanding of the gene-environment interaction which undoubtedly characterises this disease.

Acknowledgements. This research was supported by Contract N01-HC-55028 from the National Heart, Lung, and Blood Institute. The authors thank D. Robinette and the National Academy of Sciences-National Research Council Medical Follow-up Agency for providing data on height and weight from military records and from mailed questionnaires.

\section{References}

1. Rimoin DL, Rotter JI (1985) Progress in understanding the genetics of diabetes mellitus. Prog Clin Biol Res 177: 393-412

2. Rotter JI, Rimoin DL (1983) Diabetes mellitus. In: Emery AEH, Rimoin DL (eds) Principles and practice of medical genetics, Vol 2. Churchill Livingstone, Edinburgh, pp 1180-1201

3. Królewski AS, Warram JH (1985) Epidemiology of diabetes mellitus. In: Marble A, Krall LP, Bradley RF, Christlieb AR, Soeldner JS (eds) Joslin's diabetes mellitus, 12th edn. Lea and Febiger, Philadelphia, pp 12-42

4. Langenbeck $U$, Jörgensen $G$ (1976) The genetics of diabetes mellitus: a review of twin studies. In: Creutzfeldt W, Kobberling $J$, Neel JV (eds) The genetics of diabetes mellitus. Springer-Verlag, New York, pp 21-25

5. Barnett AH, Eff C, Leslie RDG, Pyke DA (1981) Diabetes in identical twins: a study of 200 pairs. Diabetologia 20: 87-93

6. Gottlieb MS, Root HF (1968) Diabetes mellitus in twins. Diabetes 17: 693-704

7. Harvald B, Hauge M (1963) Selection in diabetes in modern society. Acta Med Scand 173: 459-465

8. Then Berg H (1939) The genetic aspect of diabetes mellitus. J Am Med Assoc 112: 1091

9. Feinleib M, Garrison RJ, Fabsitz R, Christian JC, Hrubec Z, Borhani NO, Kannel WB, Rosenman R, Schwartz JT, Wagner JO (1977) The NHLBI twin study of cardiovascular disease risk factors: methodology and summary of results. Am J Epidemiol 106: 284-295

10. Feinleib M, Christian JC, Borhani NO, Rosenman R, Garrison RJ, Wagner J, Kannel WB, Hrubec Z, Schwartz JT (1976) The National Heart and Lung Institute Twin Study of Cardiovascular Disease Risk Factors: organization and methodology. Acta Genet Med Gemellol (Roma) 25: 125-128

11. Pollin W, Allen MG, Hoffer A, Stabenau JR, Hrubec Z (1969) Psychopathology in 15909 pairs of veteran twins: evidence for a genetic factor in the pathogenesis of schizophrenia and its relative absence in psychoneurosis. Am J Psychiatry 126: 43-56
12. Fabsitz R, Feinleib M, Hrubec Z (1980) Weight changes in adult twins. Acta Genet Med Gemellol (Roma) 29: 273-279

13. Allen G, Harvald B, Shields J (1967) Measures of twin concordance. Acta Genet Stat Med 17: 475-481

14. Smith $C$ (1974) Concordance in twins: methods and interpretation. Am J Hum Genet 26: 454-466

15. Harris MI (1985) Prevalence of noninsulin-dependent diabetes and impaired glucose tolerance. In: National Diabetes Data Group. Diabetes in America: diabetes data compiled 1984, NIH Publication No. 85-1468. National Institute of Arthritis, Diabetes, and Digestive and Kidney Diseases, Bethesda, Md, pp VI-1-VI-31

16. Everhart J, Knowler WC, Bennett PH (1985) Incidence and risk factors for noninsulin-dependent diabetes. In: National Diabetes Data Group. Diabetes in America: diabetes data compiled 1984, NIH Publication No. 85-1468. National Institute of Arthritis, Diabetes, and Digestive and Kidney Diseases, Bethesda, Md, pp IV-1-IV-35

17. Barnett AH, Spiliopoulos AJ, Pyke DA, Stubbs WA, Burrin J, Alberti KGMM (1981) Metabolic studies in unaffected co-twins of non-insulin-dependent diabetics. Br Med J 282: 1656-1658

18. Standards of physical examination during mobilization: mobilization regulations nos. 1-9 (1942). War Department, Washington, D. C.

19. Kendler KS, Holm NV (1985) Differential enrollment in twin registries: its effect on prevalence and concordance rates and estimates of genetic parameters. Acta Genet Med Gemellol (Roma) 34: 125-140

20. National Diabetes Data Group (1979) Classification of diabetes mellitus and other categories of glucose intolerance. Diabetes 28: 1039-1057

21. WHO Expert Committee on Diabetes Mellitus (1980) Second report, World Health Organization Tech Rep Ser 646, WHO, Geneva

22. Haffner SM, Rosenthal M, Hazuda HP, Stern MP, Franco LJ (1984) Evaluation of three potential screening tests for diabetes mellitus in a biethnic population. Diabetes Care 7:347-353

23. Rushforth NB, Bennett PH, Steinberg AG, Miller M (1975) Comparison of the value of the two- and one-hour glucose levels of the oral GTT in the diagnosis of diabetes in Pima Indians. Diabetes $24: 538-546$

24. Kirk RL, Serjeantson SW, King H, Zimmet P (1985) The genetic epidemiology of diabetes mellitus. Prog Clin Biol Res 194: 119-146

25. Smith C (1970) Heritability of liability and concordance in monozygous twins. Ann Hum Genet 34: 85-91

Received: 21 April 1987

and in revised form: 2 September 1987

Dr. Joseph V.Selby

Division of Research

Kaiser Permanente Medical Care Program

(Northern California Region)

3451 Piedmont Ave., 4th floor

Oakland, CA 94611

USA 